\title{
EHEALTH AND THE NEED FOR EDUCATION IN BIOMEDICAL AND HEALTH INFORMATICS FOR THE PHYSICIANS IN BULGARIA
}

\author{
Iskra Mircheva \\ Department of Social Medicine and Healthcare Organization, \\ Medical University of Varna
}

\begin{abstract}
INTRODUCTION: eHealth applications are numerous: electronic health records, evidence-based practice, delivering care from a distance, patient self-care, epidemiological research, healthcare management activities etc. However, the effective provision of healthcare as appropriate for the eHealth environment, needs not only suitable buildings and modern medical equipment, it also needs adequately trained healthcare staff.

The aim of this study is to assess the readiness and the willingness of Bulgarian physicians to work in an eHealth environment and to give a reason for their still present necessity of education in biomedical and health informatics.

MATERIALS AND METHODS: An enquiry was carried out in 2013 among the physicians in Bulgaria aiming at the assessment of their knowledge of using computers in their daily medical practice, their attitude to eHealth and their readiness to work in an eHealth environment.

RESULTS: The results of the study showed the positive attitude of Bulgarian physicians to information technologies (97\%) and their recognized need of using computers in medicine (91.9\%). Although $77.49 \%$ declared that they have the necessary skills and knowledge to use computers, the study proved that this is just basic computer literacy (word-processing and Internet). About half of the respondents recognize the need of additional education: databases and medical information systems $(37.64 \%)$, graphics software $(40.59 \%)$, statistical software (47.98\%), specialized medical software $(48.34 \%)$. The majority of the participants (86\%) wish to personally use computers in their daily medical practice, yet only $38.4 \%$ of them wish to enter patient data into a computer by themselves. In fact, only $17.7 \%$ are aware of the principles of eHealth.
\end{abstract}

CONCLUSIONS: Adequate education in biomedical and health informatics is one of the most important prerequisites for the successful implementation of eHealth in Bulgaria.

Keywords: Biomedical and health Informatics, eHealth, computer literacy, ICT

Address for correspondence:
Iskra Mircheva
Dept. of Social Medicine and Healthcare Organization
Faculty of Public Health
Medical University of Varna
55 Marin Drinov Str.
e-mail: mircheva_is@abv.bg

Received: February 19, 2016

Accepted: March 7, 2016

\section{INTRODUCTION}

eHealth has been defined in 2001 by Eysenbach as "an emerging field in the intersection of medical informatics, public health and business, referring to health services and information delivered or enhanced through the Internet and other related technologies." (1). Claudia Pagliari and colleagues extended this definition, including human and organizational factors as "e-health is an emerging field of medical informatics, referring to the organization 
eHealth and the Need for Education in Biomedical and Health Informatics for the Physicians in Bulgaria

and delivery of health services and information using the Internet and related technologies. In a broader sense, the term characterizes not only a technical development, but also a new way of working, an attitude, and a commitment for networked, global thinking, to improve health care locally, regionally, and worldwide by using information and communication technology" (2)

eHealth applications are numerous. They can be used for storing, managing and sharing data i.e. health information exchange and interoperability, electronic health records, computer-assisted history taking systems (3), computerized physician order entry (CPOE) $(4,5)$, support of the everyday medical practice, management of individual patients. eHealth applications can also be used to support clinical decision making, i.e. computerized decision support systems (CDSS) $(6,7,8)$, ePrescribing $(9,10)$, epidemiological research and healthcare management activities $(11,12)$. eHealth applications can also be used for delivering expert professional or consumer care remotely, i.e. telehealthcare and telemedicine (13).

The issue of eHealth remains open and much more important with the implementation of eEurope 2005 Action Plan - an information society for all, followed by the i2010 Digital Agenda for Europe (14) - one of the seven flagship initiatives of the Europe 2020 Strategy, set out to define the key enabling role that the use of information and communication technologies will have to play if Europe wants to succeed in its ambitions for 2020.

Communication of medical and health information between healthcare providers is vital to improve continuity of care. Paper-based health records are generally considered to be inadequate in an eHealth environment $(15,16)$. However, the effective provision of healthcare as appropriate for the eHealth environment, needs not only suitable buildings and modern medical equipment, it also needs adequately trained healthcare staff $(17,18,19)$. To face the challenges of eHealth, Bulgarian physicians should be adequately educated and prepared to face the challenges of eHealth.

The aim of this study is to assess the readiness and the willingness of the Bulgarian physicians to work in an eHealth environment, and to give a rea- son for their still present necessity of education in biomedical and health informatics.

\section{MATERIALS AND METHODS}

An enquiry comprising 33 questions (1 rank scaled with 5 levels of the scale and 32 questions with standardized answers) was used. The data was processed by means of IBM SPSS and STATISTICA.

Responders of the study are physicians from five regional and university hospitals in the Northeastern region of Bulgaria (Varna, Shumen, Dobrich), who are employed in the hospitals during the period November - December, 2013. The number of the participants in the study is 271 . The response rate is $82.15 \%$ (330 enquiries were sent, 271 were filled out and returned).

The study covers $10.98 \%$ of all physicians in the region. The structure of the sample correlates with the structure of all clinicians by specialization in Bulgaria (Wilcoxon Signed Ranks Test: $\mathrm{z}=-2.934$, Asymp. Sig. (2-tailed) $=0.003$ ).

In this paper, the following signs will be discussed: attitude of the clinicians to information technologies (IT), including: necessity of computers in the daily medical practice, experience and readiness to use computers, necessity of and willingness for adequate education and training to use computers, attitude to the organization and use of electronic health/ medical records, attitude to security, privacy, confidentiality and legal issues, standardization of medical data presentation, and attitude to eHealth. Some of the results are compared to the results of a similar study carried out in 1999 (20).

\section{RESULTS}

\section{Characteristics of the Sample}

The distribution of the respondents by gender is $46.9 \%$ male and $53.1 \%$ female. The largest group is that of physicians aged 50-54 years (17.71\%), followed by the age group of $40-44$ years $(15.5 \%)$ and the smallest is 60 and above 60 years $(4.43 \%)$. The young specialists (younger than 30 years) are $9.96 \%$. The other age groups are almost equal (between 13 and $14 \%)$.

About half of the respondents are from the two university hospitals in Varna (29.15\% from St. Marina hospital and $26.57 \%$ from St. Anna hospital). The structure of the sample correlates with the structure 
of all clinicians in the towns in the Northeastern region as reported by the National Statistics $(r=0.999$, $\mathrm{p}=0.003$ ). The structure of the specialties of the physicians in the sample correlates with the structure of all physicians by specialty: internal medicine $21.77 \%$, surgery $-21.4 \%$ and pediatrics $-10.33 \%$; $(\mathrm{z}=-$ 2.934, Asymp.Sig (2-tailed) $=0.003)$.

\section{Attitude of the Physicians to IT}

In this case IT is limited to computers and computer skills. This is of great importance for the proper assessment of the required level of education and training. Only $3 \%$ of the physicians have a negative attitude to IT or are afraid of it. The other $97 \%$ have a positive attitude to IT.

Necessity of Computers in the Daily Medical Practice

The majority of the respondents (91.9\%) recognize the necessity of using computers in the daily medical practice. Only $8.1 \%$ of the respondents do not understand the advantages of the computerization of the medical practice. No statistically significant relation was found between the necessity of using computers in the daily medical practice and the gender, age, place of work and specialty of the respondents.

\section{Experience and Training to Use Computers}

The majority of the physicians (84.1\%) use personally a computer in their daily work $(24.4 \%$ have a personal computer, $6.3 \%$ use their own computer, and $57.2 \%$ use a computer available in the clinic) and $15.9 \%$ do not use a computer (12.2\% do not have one, $1.1 \%$ do not know how to use it, $1.1 \%$ do not want to use a computer and $1.5 \%$ do not think that they need a computer).

While in the 1999 study $67.97 \%$ of the respondents didn't use a computer in their daily medical activities because they didn't have one, in 2013 only $12.2 \%$ didn't have a computer. However, $57.2 \%$ use a computer available in the clinic, i.e. the issue of lack of computers still remains unresolved.

Concerning the self-evaluation of their experience in using computers, $72 \%$ declared a very good (25.83\%) or sufficient (46.13\%) experience in using Internet. About two-thirds (64.21\%) declared very good $(21.77 \%)$ or sufficient $(42.44 \%)$ experience in using wordprocessing and electronic tables. Very good $(12.92 \%)$ or sufficient $(29.15 \%)$ experience in using medical information systems and data bases was declared by $42.07 \%$ and very good $(11.07 \%)$ or sufficient (35.42\%) experience in using specialized software was declared by $46.49 \%$ of the respondents. The respondents declared very little or no experience in using graphics (46.86\%) and statistical software (58.71\%), (Figure 1).

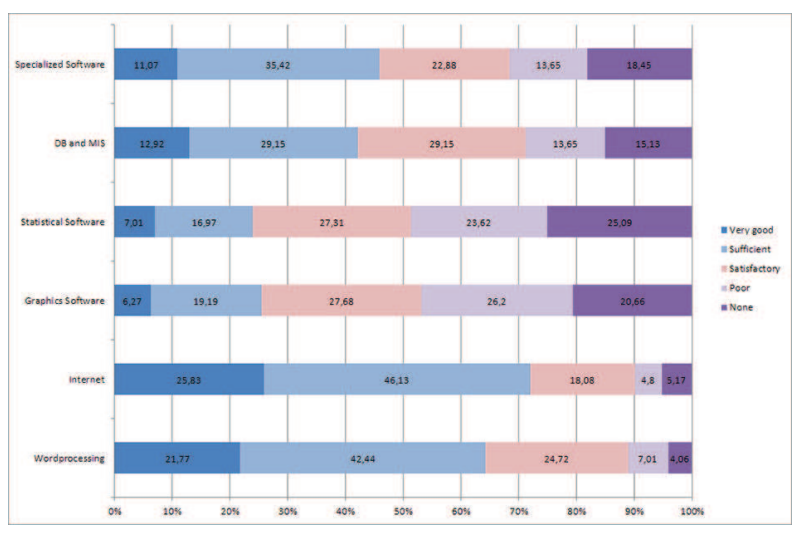

Figure 1. Experience in using computers

Statistical significance was found between the necessity of using a computer and the use of wordprocessing and electronic tables $\left(\mathrm{X}^{2}=26.287, \mathrm{p}=0.001\right)$, Internet $\left(X^{2}=17.967, p=0.021\right)$, databases and medical information systems $\left(\mathrm{X}^{2}=25.371, \mathrm{p}=0.001\right)$, as well as between the use of a computer in the daily medical practice and the experience in using wordprocessing and electronic tables $\left(\mathrm{X}^{2}=38.482, \mathrm{p}=0.001\right)$, Internet $\left(\mathrm{X}^{2}=53.803, \mathrm{p}=0.000\right)$, databases and medical information systems $\left(\mathrm{X}^{2}=40.028, \mathrm{p}=0.001\right)$ and specialized software $\left(\mathrm{X}^{2}=34.700, \mathrm{p}=0.004\right)$.

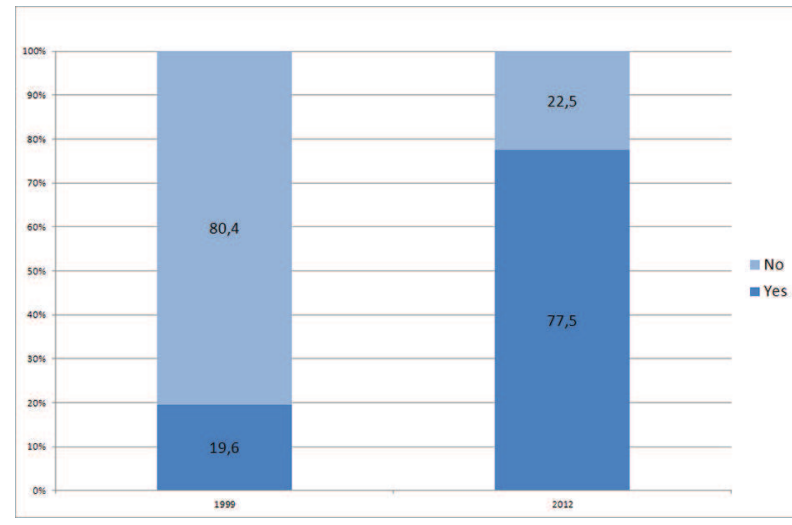

Figure 2. Adequate and sufficient experience in using computers 
eHealth and the Need for Education in Biomedical and Health Informatics for the Physicians in Bulgaria

Willingness and Necessity for Additional

\section{Education}

Although $77.49 \%$ of the respondents declared that their experience in using computers is adequate, the need for additional education and training in using computers was declared by $63.5 \%$ of them. Compared to the results of the 1999 study, the proportion of the respondents that declared adequate experience in using computers increased about four times, from $19.6 \%$ to $77.49 \%$ (Figure 2).

Additional education in wordprocessing and electronic tables need $26.57 \%$, in databases and MIS - $37.64 \%$, in graphics software - $40.59 \%$, in statistical software $-47.98 \%$ and in specialized software $48.34 \%$. Only $11.82 \%$ declared the need of additional education in using Internet (Figure 3).

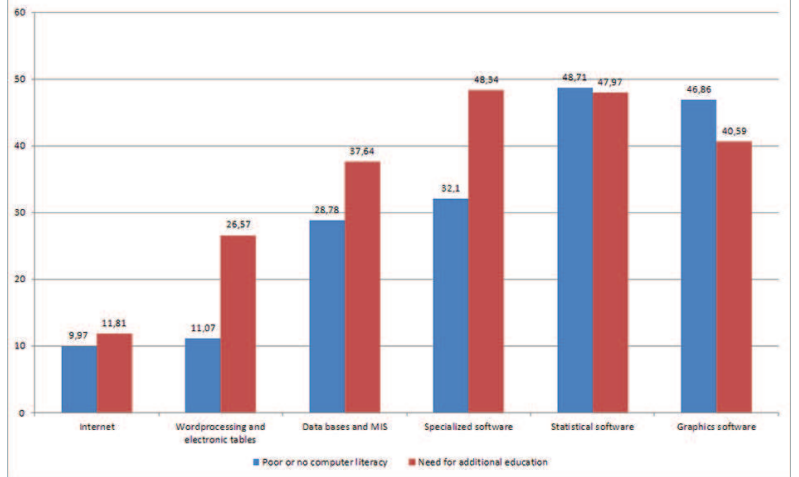

Figure 3. Computer literacy and the need for additional education

The proportion of those who recognize that they are not adequately prepared to use computers is quite large (22.51\%). However, this can be considered as a recognized necessity for additional education. The greatest need for additional education is in using specialized software and statistical software.

The majority of the participants (86\%) wish to personally use computers in their daily practice. This correlates with the demonstrated high relative ratio of clinicians with positive attitude to IT. Relatively high (14\%) is the ratio of those, who do not wish to personally use computers. However, only $38.4 \%$ of the physicians wish to enter patient data in a computer by themselves, $35.1 \%$ claim that this is not their obligation and $15.1 \%$ do not have the appropriate software.
Compared to the results of the 1999 study, twice as less physicians wish to enter patient data in a computer by themselves ( $38.4 \%$ vs $76.6 \%$ in 1999 ) in spite of the improved computer skills (11.7\% vs $84.1 \%)$ and the higher use of computers in the daily medical practice ( $84.5 \%$ vs $18.7 \%$ ) (Figure 4 ).

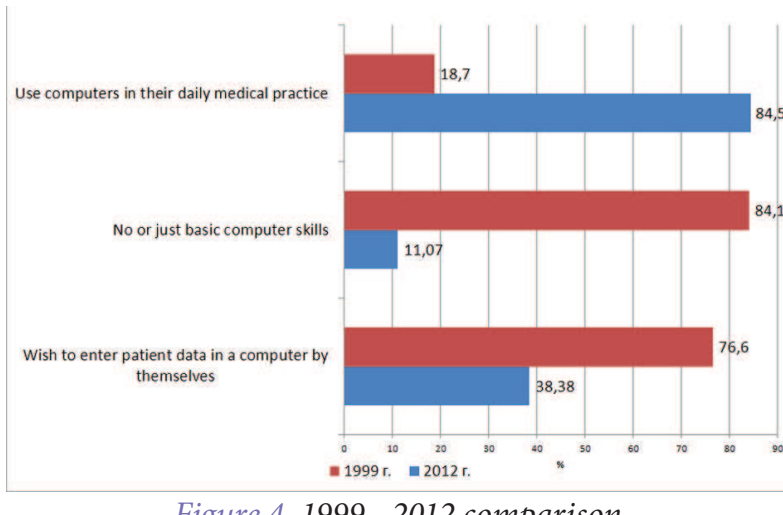

Figure 4. 1999 - 2012 comparison

Regardless of the computer skills, the willingness to be educated and use computers, $77.1 \%$ of the respondents consider that a specialized education in health informatics, is needed for the medical professionals.

Attitude to the Organization and Use of Electronic Health/Medical Records

Although $61.1 \%$ of the respondents do not use computers for entering (organizing) patient data, $90.4 \%$ recognize the need for electronic patient records.

About half of the respondents (52.4\%) state that they do not have an electronic health record system in their clinic. This is a matter of health policy, which needs to be solved on a national level. Only $13.7 \%$ use such a system in their clinic. The rest of them use a similar system only for certain characteristics: lab results $-30.6 \%$, current episode of care - $3.3 \%$, etc. This, however, is a characteristic of the hospital information system.

About half of the physicians (46.1\%) would use an electronic health record system if they have adequate software, yet, about one third of them (28.4\%) would use such a system only if they are forced do that. Another $25.5 \%$ would use such a system if they are provided with adequate software for free. 
Notwithstanding the unexpected answers, considering the use of electronic health records, the majority of the clinicians (90\%) claim the necessity of unified criteria for the organization, the structure and the content of the electronic records.

Attitude to Security, Privacy, Confidentiality and Legal Issues

Privacy, security and confidentiality of medical data are issues of great importance all over the world. The fact that $57.6 \%$ of the respondents are not acquainted with the legal issues and the measures for privacy and security of medical data actually confirms that there are not such issues. This is major negligence in our social legislation which will be aggravated with the implementation of eHealth. As for those who claim that they are acquainted with the legal issues for medical data security (42.4\%), our guess is that they have the Hippocratic Oath in mind or the Personal Data Security Act (which does not mention electronically stored medical data). Only $11.4 \%$ consider that we have the proper legislative acts concerning electronically stored medical data.

However, the majority $(85.6 \%)$ consider that privacy and confidentiality of medical data should be secured and special measures are needed. It should be noted that $14.4 \%$ of the respondents consider that no such measures are needed. This is almost twice as high compared to the 1999 study (8.2\%). Again, this puts forward the issue of the proper education of the medical professionals in health and medical informatics.

\section{Standardization of Medical Data Presentation}

The practice and the future implementation of eHealth will require that physicians should know the different standards that will allow the unified presentation of electronically stored medical data. Again, this is an issue of the national health policy which is somehow neglected. Almost one-third of the participants in the study (30.4\%) do not use other classification beside ICD-10. Another 6.64\% use DICOM, generally used for medical images by surgeons and radiologists. About 3\% use their own classification system which is somehow inappropriate. The strange thing is that $19.9 \%$ use ICPC which is usually used in primary care facilities, and is not officially recognized in Bulgaria.

\section{Attitude to eHealth}

Only $17.7 \%$ of the physicians state that they know the principles of eHealth. Nevertheless, 21.8\% consider that the country is ready for the implementation of eHealth. There cannot be another interpretation of this result except that the physicians do not know the principles of eHealth. The majority (74.5\%) think that the use of personal electronic health card (PEHC) will improve the healthcare organization and the quality of health care. The content of the PEHC, as chosen by the respondents, should contain the full electronic health record (91.5\%), health insurance data (69\%), patient demographic data (59.4\%) and data about the last episode of care (50.2\%). All answers are included within the "full electronic health record". If we are to implement eHealth, the medical professionals should be aware about the structure and the content of the electronic health records.

\section{DISCUSSION}

The high positive attitude to IT (97\%) can be taken as a prerequisite for the success of the implementation of eHealth.

The high relative ratio (91.9\%) of those, who recognize the necessity of using computers in the daily medical practice can be considered as a promising prerequisite, and a necessary condition for the implementation of eHealth. On the other hand, 8.1\% of the responders do not understand the advantages of the computerization of the medical practice. This requires that they should be trained accordingly.

The availability of a single computer in the clinic is not enough. The lack of computers is a fact that concerns almost all healthcare organizations in the country. However, the implementation of eHealth should start with the installation of computers and computer networks, followed by an adequate education of the medical staff.

The results of the study allow us to claim that our physicians have only basic computer literacy. Having in mind that basic computer literacy cannot be considered as experience in using computers, we can conclude, that only $23-25 \%$ of the participants in the study have enough experience to use computers. i.e. the majority do not have adequate knowledge and skills to use computers in their daily medical practice. 
eHealth and the Need for Education in Biomedical and Health Informatics for the Physicians in Bulgaria

The results of the study show that Bulgarian physicians are not quite acquainted with the issues of the electronic health records, security, privacy, confidentiality and legal issues, standardization of medical data presentation and they do not know the principles of eHealth. As these are all issues within the domain of health informatics, we would suggest that our physicians need to gain knowledge of health informatics.

The government should take advantage of the stated willingness to gain knowledge in using computers along with the positive attitude of the clinicians to IT. The education must exceed the limits of basic computer literacy and to lead clinicians to the nature of health informatics. Thus they will be ready to face the forthcoming quality change of the medical practice provoked by the implementation of eHealth.

Considering the need for education in health informatics, a basic tuition program was developed. The course can be presented both to medical students and physicians.

The main areas covered by the course could be summarized as follows:

* Hardware and software (including computer systems, networks, communications, software engineering);

- Basics of health informatics (including standards, coding, classification, quality assessment, medical data security);

* Information systems in medicine (including data bases and medical information systems, electronic health records systems, hospital information systems, knowledge bases, decision support systems);

* Scientific and research methods in medicine (including biostatistics, probability theory, scientific methods in medicine);

* Biosignals and medical images.

\section{CONCLUSIONS}

The results of the study, carried out among the physicians in Bulgaria present the necessity of education - basic and continuous - in the field of biomedical and health informatics as one of the most important prerequisites for the successful implementation of eHealth.
To fill in the gap in the education of medical specialists, health informatics must be presented to them as early as possible in their career i.e. as soon as they enroll as students of medicine.

\section{REFERENCES}

1. Eysenbach G., "What is e-health?" Journal of Medical Internet Research, vol. 3, no. 2, article e20, 2001.

2. Pagliari C, Sloan D, Gregor P et al. What is eHealth ?: a scoping exercise to map the field. J Med Internet Res. 2005 Mar 31;7(1):e9.

3. Pringle M. Using computers to take patient histories. BMJ 1988;297:697-698.

4. Holdsworth MT, Fichtl RE, Raisch DW, Hewryk A, Behta M, Mendez-Rico E et al. Impact of Computerized Prescriber Order Entry on the Incidence of Adverse Drug Events in Pediatric Inpatients. Pediatrics 2007;120:1058-1066.

5. Bates DW. Computerized physician order entry and medication errors: finding a balance. J Biomed Inform 2005;38:259-261.

6. Bates DW, Kuperman GJ, Wang S, Gandhi T, Kittler A, Volk L et al. Ten commandments for effective clinical decision support: making the practice of evidence-based medicine a reality. J Am Med Inform Assoc 2003;10:523-530.

7. Garg AX, Adhikari NKJ, McDonald H, RosasArellano MP, Devereaux PJ, Beyene J et al. Effects of Computerized Clinical Decision Support Systems on Practitioner Performance and Patient Outcomes: A Systematic Review. JAMA 2005;293:1223-1238.

8. Kuperman GJ, Bobb AM, Payne T, Avery AJ, Gandhi TK, Burns G et al. Medication-related Clinical Decision Support in Computerized Provider Order Entry Systems: A Review. J Am Med Inform Assoc 2006; doi:10.1197/jamia.M2170.

9. Barber N, Cornford T, Klecun E. Qualitative evaluation of an electronic prescribing and administration system. Qual Saf Health Care 2007;16:271-278.

10. Bates DW. Preventing medication errors: a summary. Am Health Syst Pharm 2007;64:S3-S9.

11. Pagliari C, Sloan D, Gregor P, Sullivan F, Detmer D, Kahan JP et al. What is eHealth (4): a scoping exercise to map the field. J Med Internet Res 2005;7:e9.

12. Pagliari C, Sloan D, Gregor P, Sullivan F, Kahan JP, Detmer D et al. Literature review and conceptual 
map of the field of eHealth. Final report to the SDO programme. 2004.

13. Hersh WR, Hickam DH, Severance SM, Dana TL, Pyle KK, Helfand M. Diagnosis, access and outcomes: Update of a systematic review of telemedicine services. J Telemed Telecare 2006;12(S2):S3-31.

14. http://ec.europa.eu/information_society/eeurope/ i2010/index_en.htm

15. Hillestad R, Bigelow J, Bower A, Girosi F, Meili R, Scoville R, and Taylor R. Can electronic medical record systems transform health care? potential health benefits, savings, and costs. Health Affairs 2005: 24(5): 1103-17.

16. Tang PC. Key capabilities of an Electronic Health Record System. Washington: National Academy Press, 2003.

17. Sheaff $R$ and Peel V. Managing health service information systems - an introduction. Buckingham: Open University Press, 1995.

18. Chaudhry B, Wang J, Wu S, Maglione M, Mojica W, Roth E, Morton SC, and Shekelle PG. Systematic review: impact of health information technology on quality, efficiency, and cost of medical care. Ann Intern Med 2006: 144(10): 742-52.

19. Westbrook JI, Braithwaite J, Gibson K, Paoloni R, Callen J, Georgiou A, Creswick N, and Robertson L. Use of information and communication technologies to support effective work practice innovation in the health sector: a multi-site study. BMC Health Serv Res 2009: 9: 201-10.

20. Feschieva N, Mircheva I. Proofs of the necessity of medical informatics for the physicians in Bulgaria . Medinfo. 2001;10(Pt 2):1019-22. 